\title{
A dicotomia sujeito-objeto no conto Negrinha, de Monteiro Lobato
}

\section{The subject-object dichotomy in the short story Negrinha by Monteiro Lobato}

\author{
Rosilda de Moraes Bergamasco*
}

\begin{abstract}
Resumo: A pesquisa empreendida apresenta uma análise sobre o conto Negrinha, do escritor brasileiro Monteiro Lobato, sob o viés dos estudos pós-coloniais. O texto narra a vida difícil levada por uma pequena órfã, filha de escrava, junto à antiga patroa de sua mãe. Diante das relações estabelecidas entre as duas personagens, de sujeito e de objeto, pretendemos aplicar a teoria da subjetificação e da objetificação, processos através dos quais podem se revelar as estratégias utilizadas pela patroa para impor-se como sujeito (agente), e que, por outro lado, também revelam as formas encontradas pela menina para deixar de ser um objeto e tornar-se um sujeito.
\end{abstract}

Palavras-chave: Crítica pós-colonial. Objetificação. Subjetificação. Lobato.

Abstract: This research analyzes from a post-colonial perspective the short story Negrinha written by the Brazilian writer Monteiro Lobato. The short story is about the difficult life of a little orphan, the daughter of a slave, with the former mistress of her mother. Considering the relations between the two characters, subject and object, the article intends to apply the theory of subjectification and objectification. This theory reveals the strategies used by the mistress to impose herself as subject (agent) as well as the ways found by the girl to stop being an object and become a subject.

Keywords: Post-colonial criticism; Objectification; Subjectification; Lobato.

\section{Considerações iniciais}

Um dos escritores mais influentes do século XX no Brasil, Monteiro Lobato (1882-1948) é considerado o precursor da literatura infantil brasileira, mais popularmente conhecido pela série Sítio do Picapau Amarelo. Dedicou-se também à escritura de contos, em geral sobre temas regionalistas (BOSI, 1973, p. 68), além de artigos, críticas, prefácios e um único romance, $O$ Presidente Negro, que não alcançou tanta popularidade quanto suas obras para crianças.

\footnotetext{
*Mestranda. Universidade Estadual de Maringá - UEM. E-mail: rosilda.demoraes@gmail.com
} 
O presente estudo se volta justamente sobre o conto Negrinha, publicado em 1920, trinta e dois anos após a abolição da escravatura no país. Esta narrativa foi publicada dentro da obra de mesmo nome, um livro de contos, considerado por muitos como contendo os melhores escritos por Lobato para o público adulto. Com esse conto, a visão de um Monteiro Lobato preconceituoso em relação à "raça" negra sucumbe e dá lugar à outra percepção em relação ao escritor.

A obra mostra a vida levada por uma pequena órfã, filha de uma ex-escrava, junto à antiga patroa de sua mãe. Tida como exemplo da boa moral e de religiosidade, a patroa estabelece com a menina uma relação de sujeito e objeto, respectivamente. Tendo como base a relação constituída entre essas duas personagens, pretendemos analisar as estratégias empregadas pela patroa para objetificar a pequena órfã e impor-se como sujeito. Por outro lado, examinaremos as estratégias utilizadas pela menina com a finalidade de descobrir sua subjetividade e desse modo tornar-se sujeito da sua própria vida.

Considerando esse propósito, entendemos que a teoria pós-colonial seja a mais apropriada para tal intento. Isso porque o contexto social em que se insere o conto a ser examinado diz respeito a um período em que a abolição da escravatura já é uma realidade. Mas, apesar disso, as marcas da escravidão estão bem visíveis no relacionamento instituído entre colonizadores e colonizados, a partir então. Assim, os ex-escravos ainda não são vistos como sujeitos, por parte da sociedade, mas sim como objetos. De acordo com Bonnici (2000):

A crítica pós-colonialista é enfocada, no contexto atual, como uma abordagem alternativa para compreender o imperialismo e suas influências, como um fenômeno mundial e, em menor grau, como um fenômeno localizado. Essa abordagem envolve: um constante questionamento sobre as relações entre a cultura e o imperialismo para a compreensão da política e da cultura na era da descolonização; o autoquestionamento do crítico, porque solapa as próprias estruturas do saber, ou seja, a teoria literária, a antropologia, a geografia eurocêntricas; engajamento do crítico, porque sua preocupação deve girar em torno da criação de um contexto favorável aos marginalizados e aos oprimidos, para a recuperação da sua história, da sua voz, e para a abertura das discussões acadêmicas para todos; uma desconfiança sobre a possível institucionalização da disciplina e sua apropriação pela crítica ocidental, neutralizando a sua mensagem de resistência. (BONNICI, 2000, p. 10). 
Em meio a toda essa abrangência da teoria pós-colonial, o enfoque será dado à dicotomia sujeito-objeto existente na relação entre colonizador e colonizado. Para tanto, tomaremos como alicerce a produção crítico-teórica de autores como Bhabha (1991), Bonnici (2000, 2005, 2009) e Todorov (1999). Uma vez munidos desse arcabouço teórico, pretendemos realizar sua aplicação em uma leitura possível da obra selecionada como corpus.

\section{Sujeito e Objeto}

O termo sujeito advém do latim sub - sob; jacere - arremessar, e está profundamente relacionado aos Estudos Pós-coloniais porque subjaz às percepções que o sujeito colonial tem de sua identidade e de sua habilidade para assumir sua posição na sociedade e revidar as atitudes e os pressupostos do colonialismo. (BONNICI, 2005, p. 52) O conceito de sujeito está presente desde a antiguidade. Com Descartes, a noção de "Penso, logo existo" contribui para a separação entre o sujeito e o objeto, entre o ser e o outro. A partir de então, o sujeito é visto como um ser autônomo, não mais manipulado por forças divinas ou cósmicas, mas sim orientado pela sua capacidade intelectual, que o faz controlar o mundo. No entanto, essa concepção não abarca a totalidade do sujeito.

Com Freud e Marx acontece a subversão do conceito de autonomia do indivíduo, pois através deles surge o conceito de produção do sujeito por meio da ideologia e do discurso. Para Marx (1982, p. 25): "Não é a consciência do homem que determina seu meio, mas, ao contrário, seu meio social que determina sua consciência." Isso porque a classe dominadora, além de dominar, fabrica as ideias através das quais ela determina como a sociedade deve ver. Assim, o sujeito desde que nasce acha-se inserido dentro de uma ideologia. Considerando isso, o sujeito acaba por acolher a ideologia imposta, em razão de esta ser a única disponível e aceita pela família e pela sociedade em que vive, bem como lhe possibilita construir sua identidade por meio da linguagem, das convenções e dos códigos sociais. (BONNICI, 2005, p. 52).

Ao colocar em relevo a importância do inconsciente, Lacan (apud BONNICI, 2005, p.53) constata que este está estruturado como a linguagem, esta por sua vez produz o significado, da mesma forma como o sujeito é produzido pela linguagem. Nesta perspectiva, a formação do sujeito pode compreender três estágios, a saber: o Imaginário, o Espelho e o Simbólico. 
O estágio do Imaginário se caracteriza pelo período em que a criança não se diferencia dos seus pais, do Outro, mas se percebe semelhante a eles. Por outro lado, o estágio do Espelho refere-se ao momento em que a criança se olha no espelho e toma consciência de que é um ser diferente de seus pais. Quanto ao estágio Simbólico, diz respeito ao momento em que a criança se insere no mundo da linguagem, se produz a partir dela, assim como é arremessada sob as leis preexistentes da linguagem. Leis essas sob as quais o sujeito terá que viver e adquirir sua identidade.

Para Foucault (idem, p. 53), a formação do sujeito e da subjetividade se dá por meio do discurso. Para ele, o discurso, concebido como um conjunto de sistemas históricos, sociais e culturais de conhecimento, apresenta uma maior abrangência do que a linguagem, contudo, essa formação do sujeito acontece do mesmo modo que a formação pela linguagem. Com Derrida (idem, p. 53), a noção de sujeito se amplia, pois, para este estudioso, a concepção de Descartes de um sujeito autônomo deve ser negada. Para Derrida, o sujeito estável não existe, pois nele há o paradoxo da ação e da passividade para reagir contra as forças externas. Mas para Fanon, Said, Spivak e Bhabha (apud BONNICI, 2005, p. 53), mesmo o sujeito sendo considerado um constructo fabricado pela exclusão, marginalização e opressão do Outro, a sua autonomia não é negada, e tais autores asseguram a independência e a liberdade do sujeito em reagir contra as forças que o oprimem.

Diante dessa dicotomia aportada na distinção entre o sujeito e o outro, nota-se que "nas sociedades pós-coloniais, o sujeito e o objeto pertencem a uma hierarquia em que o oprimido é fixado pela superioridade moral do dominador." (BONNICI, 2009, p. 265) Ou seja, o colonizador, ao entrar em contato com o colonizado, impõe-se como um sujeito poderoso, civilizado, culto, forte, dotado de saberes, como os da ciência e da literatura, ou seja, possuidor apenas de boas características. Por sua vez, o colonizado é sempre retratado de forma a fazer uma distinção negativa em relação ao colonizador, como um ser destituído de bons modos, religião, inteligência, sem linguagem, em suma, destituído de humanidade e rebaixado à espécie animal. Constitui-se, assim a dialética do sujeito (agente) e do objeto (o outro, subalterno).

Isso se deve ao fato de que para o homem europeu o sentimento de superioridade em relação aos outros povos, especialmente os chamados de "primitivos", sempre foi a base para o relacionamento com estes. De acordo com Bhabha (1991, p. 184), o discurso colonial pode ser considerado como 
um aparato do poder dominante e as condições para efetivação desse discurso referem-se a "um aparato que acende o reconhecimento e a negação das diferenças raciais/culturais/históricas." Nesse sentido, "o objetivo do discurso colonial se concentra em construir o colonizado como população de tipo regenerado, tendo como base uma origem racial para justificar a conquista e estabelecer sistemas administrativos e culturais." Para que tal objetivo se efetive, o modo de governar do colonizador compreende a apropriação, direção e dominação das várias esferas de atividade social.

O colonizado, dessa forma, é visto pelo colonizador como um ser degenerado, potencialmente indisciplinado, perigoso, em outras palavras, o outro é posicionado no discurso estereotipado colonial. Portanto, é a partir dos interesses e dos conhecimentos do colonizador em relação ao colonizado que se diferenciam e se constroem as relações entre estes. De acordo com Todorov (1999), podem ser distinguidos três eixos em que se situa a problemática dessas relações:

Primeiramente, um julgamento de valor (um plano axiológico): o outro é bom ou mau, gosto dele ou não gosto dele, ou, como se dizia na época, me é igual ou me é inferior [...]. Há, em segundo lugar, a ação de aproximação ou de distanciamento em relação ao outro (um plano praxiológico): adoto os valores do outro, identifico-me a ele; ou então assimilo o outro, impondo-lhe minha própria imagem; entre a submissão ao outro e a submissão do outro há ainda um terceiro termo, que é a neutralidade, ou indiferença. Em terceiro lugar, conheço ou ignoro a identidade do outro (seria o plano epistêmico); aqui não há, evidentemente, nenhum absoluto, mas uma gradação infinita entre os estados de conhecimento inferiores e superiores. (TODOROV, 1999, p. 223).

Quando, no relacionamento do colonizado com o colonizador, aquele é tratado como objeto, pode-se utilizar o termo subalterno para descrevê-lo. O termo subalterno, emprestado da obra de Gramsci, refere-se a todos os grupos humanos excluídos, os quais não têm voz e se encontram desunidos para lutar contra o poder hegemônico, principalmente em decorrência da notória dependência desses grupos aos grupos hegemônicos. Em decorrência dessa dependência, o colonizado deixa de ter acesso à cultura e à organização social, bem como é transformado em uma pessoa muda, já que ao sujeito subalterno não é oferecido nenhum espaço para que ele possa falar, tampouco ser ouvido pelo poder dominante. 
Mesmo diante de tal situação, o sujeito subalterno pode, de alguma forma, encontrar estratégias para sair dessa posição. De acordo com Bhabha (apud BONNICI, 2009, p. 265), "o subalterno pode falar e a voz do nativo pode ser recuperada através da paródia, da mímica e da cortesia ardilosa, que ameaçam a autoridade colonial." Ou seja, a partir do momento em que o colonizado toma consciência da sua subjetividade e enfrenta o seu opressor há a possibilidade de uma reescrita do colonizado na História, embora esse tipo de descolonização sempre seja um fenômeno violento.

De acordo com Bonnici (2000, p. 18) há três teorias que tratam da possibilidade do colonizado-objeto reverter sua posição e tornar-se sujeito e desse modo reescrever sua História. Uma das teorias refere-se à de JanMohammed, segundo a qual o autor de literatura pós-colonial deve se dedicar a produzir estereótipos negativos do colonizador e, por outro lado, criar imagens autênticas do colonizado. Através dessas estratégias, será criado um mecanismo que foi elaborado de modo inverso, mas extremamente funcional, na era colonial.

A segunda teoria é endossada por Bhabha, que se recusa a produzir essa polaridade colonizador-colonizado, pois reconhece na alteridade "a sombra amarrada" do sujeito, afinal ambos se construíram através dela. Considerando que o termo alteridade significa ser o outro, ser diferente, ou seja, manter a diversidade, pode-se inferir que é no processo diferencial que ocorre a construção do sujeito e torna-se inerente à construção dos outros. (BONNICI, 2005, p. 14).

Portanto, é a situação deste hiato existente entre o sujeito e o objeto, desse território de incertezas, que o autor pós-colonial deve explorar em sua obra e assim reconstruir seus personagens pós-coloniais. A fundamentação dessa teoria está na importância dada ao hibridismo pós-colonial, com a subversão da autoridade e a implosão do centro imperial, como base para a construção de um novo sujeito pós-colonial, dotado de consciência sobre a relação com o Outro.

A terceira teoria provém do guianense Wilson Harris, que se refere ao sujeito colonizado como uma pessoa detentora de muitas facetas, o eu e ao mesmo tempo o outro. E é através da procura por esse eu composto que o colonizado adquire uma nova identidade pós-colonial. Conforme Bonnici (2000):

A violência (o desmembramento do sujeito) é seguida pela fragmentação e pela reconstrução do vazio a partir do qual as culturas são liberadas da dialética destrutiva da história. A chave de tudo isso é a imaginação, o 
único e antigo refúgio de pessoas oprimidas pela política de dominação e de subserviência. (BONNICI, 2000, p. 18).

A teoria de JanMohammed é considerada simplista; as outras duas, por outro lado, procuram demonstrar que é possível subverter de modo radical e interno a noção de eurocentrismo e a partir daí o colonizado construir sua alteridade como sujeito e não mais ser visto como um mero objeto.

\section{A Dicotomia Sujeito-Objeto presente em Negrinha, de Monteiro Lobato}

O livro de contos Negrinha, de Monteiro Lobato, já em sua estreia, em 1920, vendeu 15 mil exemplares em três tiragens sucessivas, quando o parque gráfico da editora do autor funcionava a todo vapor. Segundo o crítico Sérgio Milliet (apud CAMARGOS; SACCHETTA, 2008, p. 11), a obra reúne "o melhor da safra de textos cada vez mais concisos, que se modernizam continuamente ao retratar o típico cotidiano brasileiro: ' $O$ humorismo e a psicologia unem-se em um estilo saboroso, rápido, elegante e claro' ". Conforme Camargos e Sacchetta, a obra, "embora apresentando uma temática variada, mantém, no seu conjunto, o mesmo ritmo na arrumação vertiginosa das palavras e no tom enxuto e vibrante". (idem, p. 12)

Especialmente no conto Negrinha vê-se aflorar em Monteiro Lobato um crítico social, disposto a denunciar um sistema escravocrata que se prolonga por anos a fio, apesar da abolição da escravatura em 1888, trinta e dois anos antes da produção da obra. O conto apresenta um painel das relações entre o colonizador e o colonizado, ou seja, as relações de sujeito e objeto. A narrativa expõe o drama vivido por Negrinha, uma menina nascida na senzala, filha de mãe escrava, que com quatro anos de idade fica órfã de mãe. Como conseqüência desse fato, torna-se dependente da "caridade" da patroa de sua mãe, que é descrita no conto pelo narrador desse modo:

Excelente senhora, a patroa. Gorda, rica, dona do mundo, amimada dos padres, com lugar certo na igreja e camarote de luxo reservado no céu. Entaladas as banhas no trono (uma cadeira de balanço na sala de jantar), ali bordava, recebia as amigas e o vigário, dando audiências, discutindo o tempo. Uma virtuosa senhora em suma - "dama de grandes virtudes apostólicas, esteio da religião e da moral", dizia o reverendo. (LOBATO, 2008, p. 18). 
Nota-se que o narrador, ao descrever essa personagem, utiliza adjetivos positivos para caracterizá-la, ou seja, apresenta-a como uma senhora caridosa, religiosa. Ao apresentar Negrinha, o narrador relata: "Negrinha era uma pobre órfã de sete anos. Preta? Não; fusca, mulatinha escura, de cabelos ruços e olhos assustados." (idem, p. 18). Há nesse trecho uma característica importante de Negrinha: "olhos assustados". Mais adiante o narrador relata: "Assim cresceu Negrinha - magra, atrofiada, com os olhos eternamente assustados." (ibidem) Há nessa afirmação um reforço na caracterização dos olhos de Negrinha "eternamente assustados".

Essa descrição de Negrinha gera uma contradição no texto: se a patroa, dona Inácia, é descrita pelo narrador como uma pessoa religiosa, virtuosa, como é possível Negrinha ser uma menina com "olhos eternamente assustados"? A convivência de Negrinha com uma senhora tão caridosa não deveria trazer tranquilidade, paz, alegria à menina? Por que o susto nos olhos?

Assim, a constituição da dicotomia sujeito/objeto, dentro do conto, revela-se de modo bem explícito na descrição das personagens - D. Inácia e Negrinha. Inicialmente, D. Inácia não é apresentada pelo seu nome, mas sim como sendo a patroa, ou seja, pela sua posição hierárquica de superioridade em relação a Negrinha. Por outro lado, à menina é dado um nome que apenas remete à cor da sua pele, demonstrando assim uma forma de inferiorizá-la. Nesse sentido, pode-se afirmar que a patroa é retratada como sendo o sujeito, como uma pessoa de moral, poderosa, culta, religiosa, civilizada, em suma, possuidora de apenas boas características. Já Negrinha é retratada de forma oposta, como um objeto, principalmente pela aparência que apresenta: "magra, atrofiada", "cabelos ruços, olhos assustados", ou seja, destituída de características positivas e de dignidade. Configura-se, desse modo, uma relação desigual entre as duas personagens, nos papéis de colonizador e colonizado.

O conto mostra que "o 13 de Maio tirou-lhe das mãos [de dona Inácia] o azorrague, mas não lhe tirou da alma a gana.” (idem, p. 19). Ou seja, a alma da "dama de grandes virtudes apostólicas" não era tão pura quanto aparentava socialmente. Se de um lado a abolição da escravatura tirou-lhe o direito de maltratar os escravos, de outro não acabou com sua aversão aos negros. Assim, o narrador procura, através da ironia, denunciar a hipocrisia existente na sociedade e na Igreja da época.

Dona Inácia, para impor-se como sujeito, como a pessoa que detém o poder sobre o outro, impede que Negrinha demonstre qualquer tipo de 
manifestação em face do drama que vive. Primeiramente, a patroa, através do seu discurso, procura impedir o choro da menina, quando esta é ainda um bebê: “- Quem é a peste que está chorando aí?”. Para acalmar a cólera da patroa, "a mãe da criminosa abafava a boquinha da filha e afastava-se com ela para os fundos do quintal, torcendo-lhe em caminho beliscões de desespero. - Cale a boca, diabo!" (idem, p. 18). Assim, percebe-se que Negrinha, desde o seu nascimento, precisa manter-se afastada da patroa, principalmente quando esta ouvia "aquele choro [que] nunca vinha sem razão. Fome quase sempre, ou frio, desses que entanguem pés e mãos e fazem-nos doer...". (ibidem).

Nestas condições cresce Negrinha e após a morte de sua mãe a situação piora. Não tem ninguém para protegê-la da patroa e "por ali ficou feito gato sem dono, levada a pontapés." (ibidem, p. 18). Nem mesmo brincar Negrinha não podia: "Com pretextos de que às soltas reinaria no quintal, estragando as plantas, a boa senhora punha-a na sala, ao pé de si, num desvão da porta." (idem, p. 19). Negrinha, então, devia ficar sentada, imóvel, durante horas e sem poder abrir a boca, falar. Portanto, Negrinha pode ser considerada uma subalterna, pois caracteriza-se por estar excluída das atividades sociais, sem direito a falar ou ser ouvida pela patroa, e principalmente por estar impossibilitada de lutar contra os desmandos de Dona Inácia, já que dependia diretamente dela para "viver". Com isso, acaba sendo impedida de ter acesso à cultura e à vida social.

Essa é uma das formas do colonizador, do sujeito, constituir o outro como objeto, ou seja, concebendo o outro como um ser diferente, inferior a ele. Neste caso, em razão da "raça" de Negrinha, a patroa procura dominar e restringir as atividades humanas e sociais da menina, impedindo com isso que esta exerça sua subjetividade. Isso porque Negrinha é vista por Dona Inácia através do prisma do discurso estereotipado colonial - como um ser degenerado, indisciplinado, perigoso, em razão da sua cor. Assim, é a partir dos interesses e dos conhecimentos da patroa em relação à Negrinha que o relacionamento entre as duas personagens se efetivará e se diferenciará.

Nesse sentido, os três eixos referentes à relação entre colonizador e colonizado, concebidos por Todorov, podem ser notados na relação constituída entre Dona Inácia e Negrinha. No que se refere ao plano axiológico, percebe-se que a patroa julga-se superior à Negrinha, por isso considera-a má e não gosta dela. No plano praxiológico, nota-se que a patroa não se identifica com Negrinha, pois a concebe como um ser inferior e, em razão disso, impede-a de exercer sua subjetividade. Por sua vez, Negrinha submete-se às ordens e 
vontades de Dona Inácia, afinal ela não se enxerga como sujeito, como uma pessoa semelhante à patroa. Em relação ao plano epistêmico, pode-se afirmar que Dona Inácia ignora a identidade de Negrinha e por essa razão trata-a como um objeto, e também Negrinha não tem noção da sua própria identidade e provavelmente por isso se deixa objetificar.

Outra estratégia utilizada para objetificar Negrinha é através dos inúmeros apelidos depreciativos que lhe dão, como "pestinha, diabo, coruja, barata descascada, bruxa, pata-choca, pinto gorado, mosca-morta, sujeira, bisca, trapo, cachorrinha, coisa-ruim, lixo." (idem, p. 19). Tinham prazer em se utilizar das palavras para agredi-la, e isso fica bem claro, por exemplo, quando the colocam o apelido de "bubônica", mas como Negrinha acaba achando "linda a palavra", por fim acabam retirando essa palavra do rol de apelidos, somente para que o apelido não produzisse efeito contrário à humilhação pretendida.

Negrinha é sempre alvo de agressões pelos adultos e ela não compreende os motivos de tanta crueldade: "Não compreendia a ideia dos grandes. Batiam-lhe sempre, por ação ou omissão. A mesma coisa, o mesmo ato, a mesma palavra provocava ora risadas, ora castigos." (ibidem). Conforme assinala Del Priore (2004, p. 97): “O castigo físico em crianças não era nenhuma novidade no cotidiano colonial. Introduzido, no século XVI, pelos padres jesuítas, para horror dos indígenas que desconheciam o ato de bater em crianças [...]”.

Assim, uma das estratégias mais eficazes empregadas pela patroa (mas não somente por ela) para tornar Negrinha uma subalterna é o uso da violência física.

O corpo de Negrinha era tatuado de sinais, cicatrizes, vergões. Batiam nele os da casa todos os dias, houvesse ou não houvesse motivo. Sua pobre carne exercia para os cascudos, cocres e beliscões a mesma atração que o imã exerce para o aço. Mãos em cujos nós de dedos comichasse um cocre, era mão que se descarregaria dos fluidos em sua cabeça. De passagem. Coisa de rir e ver a careta... . (idem, p. 18).

O conto revela que a "excelente dona Inácia era mestra em judiar de crianças. Vinha da escravidão, fora senhora de escravos - e daquelas ferozes, amigas de ouvir cantar o bolo e estalar o bacalhau. Nunca se afizera ao regime novo - essa indecência de negro igual a branco e qualquer coisinha: a polícia!" (ibidem). Ou seja, mesmo não podendo mais agredir tão duramente os negros como na época da escravidão, Dona Inácia desconta seu impedimento 
agredindo Negrinha. Nessa passagem nota-se que o sujeito, Dona Inácia, sente prazer, divertimento, em ser cruel, em bater em outro ser humano. Afinal, ela sente-se superior ao negro, considera uma "indecência de negro igual a branco". Assim, sente-se no direito de humilhar, machucar o outro:

Tinha de contentar-se com isso, judiaria miúda, os níqueis da crueldade. Cocres: mão fechada com raiva e nós de dedos que cantam no coco do paciente. Puxões de orelha: o torcido, de despegar a concha (bom! bom! bom! gostoso de dar) e o a duas mãos, o sacudido. A gama inteira dos beliscões: do miudinho, com a ponta da unha, à torcida do umbigo, equivalente ao puxão de orelha. A esfregadela: roda de tapas, cascudos, pontapés e safanões a uma-divertidíssimo! A vara de marmelo, flexível, cortante: para "doer fino" nada melhor! . (idem, p. 20).

Mesmo quando Negrinha tenta reverter essa situação, o resultado são mais agressões. Há o episódio em que Negrinha se revolta porque outra criada da casa lhe furta do prato um pedacinho de carne. Como forma de demonstrar sua insatisfação, Negrinha utiliza um dos seus apelidos e chama a criada de "peste". Imediatamente vem o castigo aplicado por Dona Inácia, que ansiava por ter uma oportunidade de impor "um castigo maior para desobstruir o fígado e matar as saudades do bom tempo." (ibidem) Para isso, a patroa "gozando-se na prelibação", coloca um ovo para ferver na água. Após o ovo chegar ao ponto certo, ela chama Negrinha, manda que abra a boca e coloca o ovo "pulando" dentro da boca da menina. "E antes que o urro de dor saísse, suas mãos amordaçaram-na até que o ovo arrefecesse. Negrinha urrou surdamente, pelo nariz. Esperneou. Mas só. Nem os vizinhos chegaram a perceber aquilo." (ibidem).

Nota-se, pois, que a personagem Negrinha não tem voz, cresce muda, pois nenhum espaço lhe é dado para que se expresse, pelo contrário, qualquer forma utilizada para se fazer ouvir é imediatamente bloqueada cruelmente. As palavras lhe são tiradas, nem mesmo um nome digno ela recebe, é chamada por um nome que representa a sua cor, mais uma forma de estereótipo. Essa é mais uma das estratégias utilizadas pelo sujeito para objetificar o outro, ou seja, a patroa, ao impedir que Negrinha se expresse, nega-lhe a possibilidade de construir sua identidade através da linguagem.

Mas chega o momento em que Negrinha enfim consegue se enxergar como pessoa, não mais como um objeto sem vida, sem alma. Esse momento surge quando duas sobrinhas de Dona Inácia, "pequenotas, lindas meninas 
louras, ricas, nascidas e criadas em ninho de plumas", (idem, p. 21) vão passar as férias de dezembro com a tia. Impedida de brincar com as meninas, Negrinha sofre por ter a infância perdida. Ao ver os brinquedos das sobrinhas, Negrinha se vê em outro mundo. Um mundo que não lhe pertence, mas que a encanta. Não consegue conter-se e, num momento que a senhora sai da sala, Negrinha esquece as torturas já recebidas e aproxima-se para ver uma boneca de louça. Nunca tinha visto algo semelhante, por isso as meninas riem da sua ingenuidade, mas a deixam pegar a boneca. Através do contato com a boneca Negrinha se dá conta que tem uma alma:

Divina eclosão! Surpresa maravilhosa do mundo que trazia em si e que desabrochava, afinal, como fulgurante flor de luz! Sentiu-se elevada à altura de ente humano. Cessara de ser coisa - e doravante ser-lhe-ia impossível viver a vida de coisa. Se não era coisa! Se sentia! Se vibrava! (idem, p. 25).

O contato com um brinquedo, especialmente com a boneca que possui um simbolismo todo especial para uma menina, Negrinha descobre a sua subjetividade, deixa de ser um objeto, uma "coisa", para se tornar humana. Assim, a partir do momento em que Negrinha tem oportunidade de ser criança como as outras meninas, de brincar com uma boneca, é que ela deixa de se ver como um objeto e se percebe como uma criança com sentimentos e desejos iguais aos das outras crianças.

Nesse instante Negrinha deixa de ter olhos assustados para ter olhos nostálgicos, em outras palavras, ela deixa de sentir medo e torna-se triste. Afinal, ao mesmo tempo em que se percebe como um ser humano e deixa de se sentir inferior a Dona Inácia, Negrinha percebe também que não havia espaço para ela desenvolver e construir sua identidade. O refúgio que ela encontra é na sua imaginação, nos seus sonhos, como forma de resgatar sua subjetividade.

Como afirma Bonnici (2000, p.18), é na imaginação que o ser oprimido encontra refúgio para amenizar suas dores: "Acalentara, dias seguidos, a linda boneca loura, tão boa, tão quieta, a dizer mamã, a cerrar os olhos para dormir. Vivera realizando sonhos da imaginação. Desabrochara-se de alma." (idem, p. 26). Foi sonhando, delirando, que Negrinha acaba encontrando como saída - a morte. Nesse sentido, a morte de Negrinha representa também uma estratégia de subjetificação, provavelmente a única encontrada pela menina para tornar-se efetivamente livre, tornar-se sujeito da sua história e alcançar seus sonhos infantis: 
Morreu na esteirinha rota, abandonada de todos, como um gato sem dono. Jamais, entretanto, ninguém morreu com maior beleza. O delírio rodeou-a de bonecas, todas louras, de olhos azuis. E de anjos... E bonecas e anjos redemoinhavam-lhe em torno, numa farândola do céu. Sentia-se agarrada por aquelas mãozinhas de louça - abraçada, rodopiada. (idem, p. 26).

Portanto, ao tomar consciência da sua subjetividade, Negrinha não consegue mais viver como um objeto e por isso acaba morrendo, pois ela não consegue enfrentar sua opressora de outra forma, já que ser negra dentro de uma sociedade na qual essa "raça" só era vista através de uma conotação negativa, significava ser sinônimo de exclusão, ou seja, sem espaço para estabelecer sua alteridade como sujeito e não ser vista meramente como objeto.

\section{Considerações finais}

Este estudo procura perceber como o colonizador, para impor-se como sujeito, como ser de "raça" superior à do negro, utiliza-se de várias estratégias para mostrar a sua superioridade. No conto analisado, o sujeito faz do outro um objeto através da violência, da tortura, da criação de estereótipos, impedindo desse modo que o subalterno se expresse, se revolte. Ou seja, o sujeito utiliza todas as formas possíveis para tornar o outro um objeto, uma coisa. Afinal, é por meio do sujeito que o subalterno se enxerga. Nota-se que o discurso do colonizador é empregado para causar humilhação, para maldizer, apelidar depreciativamente, ou seja, para caracterizar o colonizado como um ser destituído de qualidades positivas, apenas negativas.

Por outro lado, o subalterno é impedido de utilizar as mesmas estratégias para subverter sua posição hierarquicamente inferior. Portanto, o sujeito tenta tornar o outro um ser mudo, sem voz, um subalterno. É isso que ocorre no conto analisado. Negrinha é impedida de falar em qualquer circunstância, principalmente se for para reclamar dos maus-tratos. Mesmo quando é torturada covardemente pela senhora, esta a impede de manifestar sua dor, amordaçando-a.

Observou-se também que a subalterna Negrinha conseguiu deixar de se ver como uma coisa e enfim se enxergou como um sujeito. Por isso, decide que não vai, não quer, não suporta mais viver como um objeto. Ao tomar consciência da sua subjetividade, Negrinha perde a vontade de viver, pois 
sabe que dentro do meio em que vive não conseguirá construir sua identidade, assumir sua posição na sociedade e revidar as atitudes e os pressupostos colonialistas. Portanto, a única estratégia que encontra para se libertar das opressões é a morte.

A análise do conto revelou, por outro lado, a posição do narrador em face do drama vivido pela personagem Negrinha. O narrador utilizou-se da ironia para desmascarar a sociedade hipócrita da época, que pretendia aparentar ser fundamentada na religião, na cristandade, porém, nas suas características, nas suas atitudes, demonstrava cultivar valores totalmente colonizadores, dominadores, desumanos e preconceituosos em relação ao outro.

\section{Referências}

BHABHA, Homi K. A questão do "outro": diferença, discriminação e o discurso do colonialismo. In: HOLLANDA, H. B. de. (Org.). Pós-modernismo e política. Rio de Janeiro: Rocco, 1991. p. 177-203.

BONNICI, Thomas. Conceitos-chave da teoria pós-colonial. Maringá, PR: Eduem, 2005.

O pós-colonialismo e a literatura: estratégias de leitura. Maringá, PR: Eduem, 2000.

. Teoria e crítica pós-colonialistas. In: BONNICI, Thomas; ZOLIN, Lúcia Osana.

(Orgs.). Teoria literária: abordagens históricas e tendências contemporâneas. 3. ed. rev. e ampl. Maringá, PR: Eduem, 2009.

CAMARGOS, Márcia; SACCHETTA, Vladimir. O polemista do conto. In:

Negrinha. São Paulo: Globo, 2008. p. 10-14. Disponível em: <http://books.google.com.br/ books>. Acesso em: 05 agosto 2009.

DEL PRIORE, Mary. (Org.). O cotidiano da criança livre no Brasil entre a Colônia e o Império. In: __ História das crianças no Brasil. 4. ed. São Paulo: Contexto, 2004. p. 84-106.

LOBATO, Monteiro. Negrinha. In:

Negrinha. São Paulo: Globo, 2008. p. 18-26.

Disponível em: <http://books.google.com.br/books>. Acesso em: 05. ago. 2009.

MARX, Karl. Para a crítica da economia política. São Paulo: Abril Cultural, 1982.

TODOROV, Tzvetan. A questão do outro: a conquista da América. 2. ed. São Paulo: Martins Fontes, 1999.

Recebido para publicação em 8 nov. 2010.

Aceito para publicação em 2 fev. 2011. 